\title{
Assessing the effects of Farmer Field Schools on farmers' trajectories of change in practices
}

\author{
Teatske Bakker $^{1,2}$ (D) Patrick Dugué ${ }^{1,2} \cdot$ Stéphane de Tourdonnet ${ }^{3}$ \\ Accepted: 8 January 2021 / Published online: 3 March 2021 \\ (C) INRAE and Springer-Verlag France SAS, part of Springer Nature 2021, corrected publication 2021
}

\begin{abstract}
In West Africa, farmers face challenges to innovate and change their practices toward more sustainable cropping systems. Farmer Field Schools (FFS), an advisory service based on participatory principles, aim to support farmers' innovation. This study investigates farmers' innovation by characterizing their trajectories of change in agricultural practices after they participated in FFS. Two contrasting types of FFS for family farmers in the cotton-growing area of West Africa were selected. The FFS differed in how they were implemented; farmer participation was either consultative (farmers participated little in developing the FFS curricula and structure) or collaborative (farmers participated actively in developing the FFS curricula and structure). Former FFS participants were interviewed on their successive changes in cropping practices over a 4 to 8 -year time span. The sample included seven FFS on rainy season cropping (17 interviews in Burkina Faso, 22 in Togo), and four vegetable gardening FFS (21 interviews in Togo). The Efficiency-Substitution-Redesign framework was applied to pest management, organic and mineral fertilization and legume cropping practices. Our results show that the way FFS were implemented influenced farmers' trajectories of change in practices. After consultative FFS, changes in practices were limited. After collaborative FFS, we found a variety of changes in the production and use of compost, biopesticides, and inclusion of legumes in the cropping system through intercropping or pure cropping. Redesign of cropping systems included increasing on-farm compost production, collective pest management, and crop rotations. Collaborative FFS can be seen as step-by-step design processes for locally adapted cropping systems. This is the first time that farmers' trajectories of change in practices are used to assess the effects of FFS. This approach is valuable for understanding farmers' decision making and the role of participatory innovation support initiatives such as FFS.
\end{abstract}

Keywords Innovation support · Advisory services $\cdot$ Impact evaluation $\cdot$ Agroecology $\cdot$ Transition $\cdot$ Technology transfer $\cdot$ Burkina Faso $\cdot$ Togo $\cdot$ Rainy season $\cdot$ Vegetable gardening

\section{Introduction}

Supporting agricultural innovation has become extremely important, especially to tackle the challenges facing smallholder farming in Sub-Saharan Africa (Hounkonnou et al. 2012). Innovation is defined here as a process of technical and institutional change at the farm and higher system levels that influences productivity, sustainability and poverty reduction

Teatske Bakker

teatske.bakker@cirad.fr

1 CIRAD, UMR INNOVATION, F-34398 Montpellier, France

2 Univ Montpellier, F-34090 Montpellier, France

3 INNOVATION, Univ Montpellier, CIRAD, INRAE, Institut Agro, Montpellier, France
(Röling 2009). Supporting innovation is a particularly effective means to promote agroecological transitions toward sustainable production systems that also are economically viable and socially just (Altieri 2002). Agroecology relies on ecosystem function principles that may require the redesign of the agroecosystem at various scales (Tittonell 2014). These agroecological principles challenge assumptions about how knowledge is produced and used, and require farmers to find their own solutions and adapt their practices to changes in their own context (Warner 2007; Catalogna et al. 2018).

By providing a framework to analyze and design support for agricultural innovation, the agricultural innovation system (AIS) approach acknowledges contributions made by all stakeholders involved in knowledge development (Klerkx et al. 2010; Hounkonnou et al. 2012). However, the majority of AIS literature focuses on organizational and social aspects at levels above that of the farm (Schut et al. 2014; Kilelu et al. 
2014), and these same studies tend to consider innovation to be a collective process of creation (Toillier et al. 2018). Farmers' innovation processes have been far less studied at the farm scale than collective learning processes.

Supporting on-farm innovation processes is nonetheless the focus of several initiatives using either a top-down perspective or participatory approaches. As agroecology is not a set of pre-defined techniques, but relies instead on principles to manage the agroecosystem, farmers' participation is particularly important to optimize the configuration of farming systems (Warner 2007). Participatory action research initiatives aim to produce local knowledge, help stakeholders find their own solutions, and get farmers to reconsider their practices along the way (Berthet et al. 2016). Since the paradigm shift from technology transfer approaches (Rogers 2003) to more participatory and group-based approaches, advisory services have aimed to better account for farmers' demands (Birner et al. 2009). Farmer Field Schools (FFS), a participatory field-based approach, are emblematic of this shift toward more farmer-centered advisory services (Fig. 1). In FFS, groups of farmers meet routinely with a trained facilitator (technician or farmer) in the "FFS field" for practical training during one or several production cycles. FFS seek to support farmers' competences and rely on field observations, collective action and experiential learning (Van den Berg and Jiggins 2007). FFS have been used in several countries by the FAO and other international agencies, national governments and NGOs on various topics, and their implementation varies (Waddington et al. 2014).

It is important to assess the effects of innovation support initiatives such as FFS on farmers' choices and performance from both technological and social perspectives. However, the link between such initiatives and farmers' actual innovation is not clear and has rarely been studied in Africa (Glover et al. 2016). Better understanding this link requires identifying farmers' changes in practices at the cropping system and farming system levels, and consequently the definition of relevant indicators of change in each context. Farmers' innovation can be studied at a given moment in time, for example through innovation tracking (Salembier et al. 2016), or over time, highlighting how successive changes in farmers' practices lead to a transition of the farm (Lamine 2011; Chantre et al. 2015). However, relatively few data are available on farmers' changes in practices over time in West Africa. Moreover, the usual impact assessments made after the completion of an innovation support initiative like FFS often fail to grasp the temporal dynamics of farmers' changes in practices, although some adoption studies integrate temporal dynamics (Kiptot et al. 2007). Instead, most studies focus on demonstrating knowledge acquisition by farmers, or consider changes in practices in terms of adoption of a particular technique, or use indicators of economic or agronomic performance as proxies. Although necessary, most assessment methods offer only a partial view of a complex situation that focuses on the agricultural effects of an innovation support intervention (Mancini et al. 2007; Glover et al. 2016).

Increasing interest in more integrative assessment methods has led to the development of alternative impact assessment approaches (Mancini and Jiggins 2008). The analysis of temporal dynamics in farmers' changes in practices may be useful to identify triggers of change, constraints to adoption, and adaptations of practices to the farmer's own priorities (Chantre et al. 2015; Mawois et al. 2019). Such a comprehensive assessment of an innovation support intervention can also
Fig. 1 Farmer Field Schools (FFS) are a participatory fieldbased approach that seek to support farmers' competences and rely on field observations, collective action and experiential learning (Photo: T. Bakker)

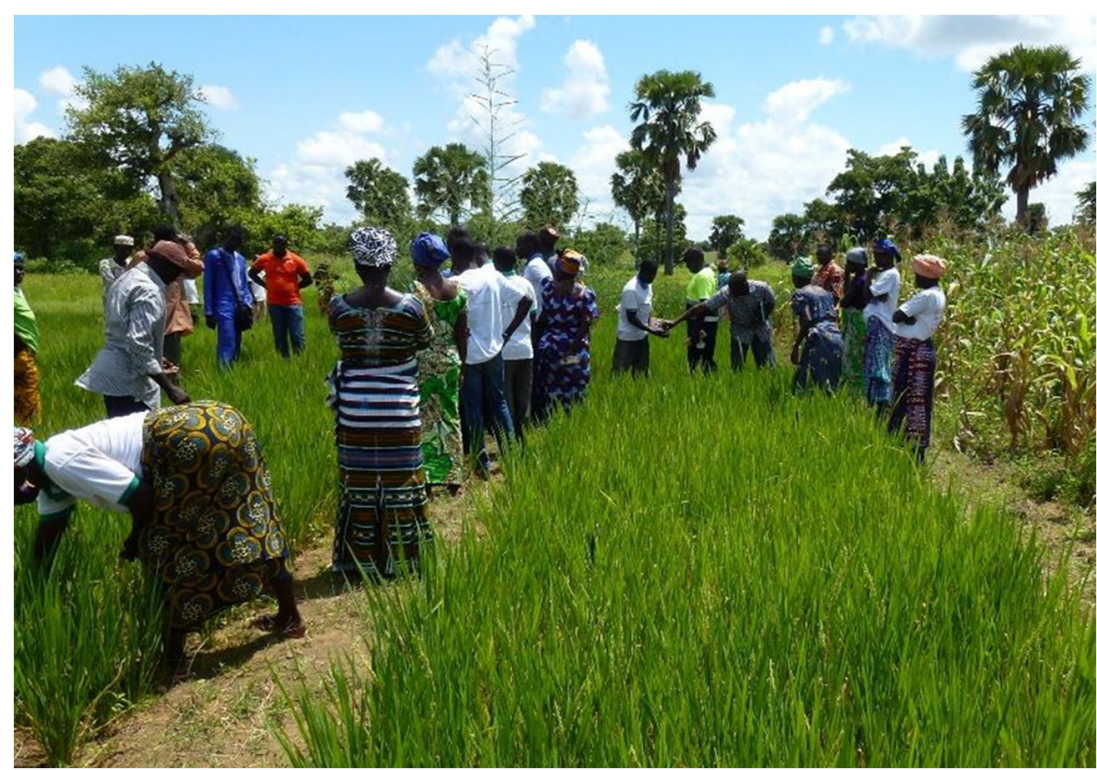


help understand how differences in the implementation of innovation support initiatives lead to differences in farmers' trajectories of change in practices.

This work aims to analyze farmers' trajectories of change in agricultural practices to assess the effects of two contrasting implementations of FFS on farm-scale agricultural innovation and agroecological transition. Two contrasting types of FFS implementation were selected. They differed with regard to whether farmers' participation in the FFS process could be characterized as being consultative or collaborative. We focus on farmers' trajectories of change in practices to better understand farmers' decision making, highlight the influence of FFS on farmers, and overcome the limits of existing FFS assessments. The remainder of the article is structured as follows: we first describe the issues concerning farmers' innovations in a cotton growing area in West Africa and the FFS implemented. We then characterize farmers' trajectories of change in practices in light of the innovation processes and the implementation of the FFS analyzed. Finally, we discuss the relevance of our approach with respect to FFS assessment methods.

\section{Material and methods}

\subsection{Contrasting FFS for family farms in the cotton area of West Africa}

The survey was conducted in 2018 and 2019 in northern Togo and western Burkina Faso, two parts of the West African cotton belt, which made it possible to compare contrasting implementations of FFS in similar soil-climatic conditions. Staple crops (maize, sorghum) and cash crops (cotton, sesame, soybean) are grown in the rainy season from May to October. Cowpea is the most frequently grown legume. Vegetables (tomatoes, onions, cabbages, chili peppers) are generally irrigated manually from November to March in areas close to cities and in bottomlands. Family farming systems include one or several households and are characterized by different sub-systems (livestock systems, rainy season and vegetable cropping systems and/or processing systems) that operate individually (livestock, individual plots) or collectively (family plots), while sharing some land, material and workforce resources. Biomass fluxes and soil fertility management are important issues due to shared access to pasture and limited access to transport, biomass and manure (Blanchard et al. 2017). The use of draft animals is widespread, almost systematic, but resource-constrained farms do not own oxen or animal-drawn tools.

The FFS in the two agricultural situations studied differed (Table 1). In Burkina Faso, the three FFS we analyzed were part of a large-scale initiative to promote "good agricultural practices" in integrated production and pest management launched in 2009 by the FAO in collaboration with the cotton producers organization (UNPCB). Working with the national research institute (INERA) and the Ministry of Agriculture, this initiative identified as its objective better cotton productivity at least cost while preserving the environment. The curriculum was defined before the FFS were set up in the villages by the project staff and the regional extension services with the expertise of INERA researchers. The curriculum centered on annual use of manure, non-conventional cotton pest management practices (biopesticides, insect counting) and the inclusion of legumes in crop rotations. It originally focused on the cotton-maize-Mucuna pruriens (a forage and cover crop) crop rotation, but Mucuna was later replaced by cowpea or soybean. The FFS set-up compared a "good agricultural practices" cropping system with three crops in rotation (annual manure input on maize and cotton, recommended dose of mineral fertilizer, biopesticides and threshold treatment for cotton) with a "farmers' practices" plot (little to no organic fertilizer, synthetic pesticides at recommended doses, variable doses of mineral fertilizer depending on the farmers' resources). This was followed by a phase of training master trainers, who subsequently trained other trainers, either technicians or farmer facilitators.

In Togo, the NGO "Agronomes et Vétérinaires Sans Frontières" (AVSF), working with a local farmers organization (UROPC-S) and the Togolese agricultural extension institute (ICAT), launched the 2014-2017 "Durability and resilience for family farms in northern Togo" project. The aim was to fight against the degradation of arable land and promote farm resilience through agroecological practices. FFS were included to help farmers improve their rainy season and gardening cropping systems, without specifying the curricula. At the effective start of project activities, groups were set up and FFS locations were identified. The facilitators were the technicians of the project and the ICAT advisor for each village. A participatory diagnosis was conducted in each group, including farmers' actual practices, their interests, and the production potential of the chosen plot. The result was that the curriculum for each FFS was different, although some transversal themes remained, for example, pest management, fertilization practices, legume cropping and crop rotation. The FFS set-up included between six and eight plots depending on the FFS, and the farmers' practices were compared by measurements in some of the participants' fields to acknowledge the variability of practices used in a single village (there was no "farmers' practices" plot). For rainy season FFS, farmers tested different cereal-legume intercropping in alternate rows (for example, 2-5 rows of maize intercropped with 1 row of soybean) or seed holes (2-4 holes for maize /1 hole for soybean), which were compared with pure cropping of maize and soybean. Particular attention was paid to gender roles as the intercropped legumes are usually grown and managed by women, therefore the proportion of legumes was maintained 
Table 1 Characteristics of the selected Farmer Field Schools (FFS) and sample of former FFS participants ( $M$ men; $W$ women) in western Burkina Faso and northern Togo. The FFS type refers to the level of farmers' participation in the FFS process (Biggs, 1989). Each line is a different locality

\begin{tabular}{|c|c|c|c|c|c|c|c|c|c|}
\hline \multirow{2}{*}{$\begin{array}{l}\text { FFS } \\
\text { Code }\end{array}$} & \multirow[t]{2}{*}{ Country } & \multirow[t]{2}{*}{ FFS type } & \multirow[t]{2}{*}{ FFS dates } & \multicolumn{2}{|l|}{ Crops } & \multicolumn{2}{|l|}{ Participants } & \multicolumn{2}{|l|}{ Sample size } \\
\hline & & & & Rainy season & Gardening & Rainy season & Gardening & Rainy season & Gardening \\
\hline FFS T1 & \multirow[t]{4}{*}{ Togo } & \multirow{4}{*}{$\begin{array}{l}\text { Collaborative } \\
\text { participa- } \\
\text { tion }\end{array}$} & \multirow[t]{4}{*}{$2015-2017$} & $\begin{array}{l}\text { Rice, maize, } \\
\text { soybean }\end{array}$ & $\begin{array}{r}\text { Tomato, } \\
\text { onion }\end{array}$ & $30(21 \mathrm{M}, 9 \mathrm{~W})$ & $18(10 \mathrm{M}, 8 \mathrm{~W})$ & $9(5 \mathrm{M}, 4 \mathrm{~W})$ & $4(2 \mathrm{M}, 2 \mathrm{~W})$ \\
\hline FFS T2 & & & & \multirow[t]{2}{*}{$\begin{array}{l}\text { Maize, } \\
\text { soybean }\end{array}$} & Tomato & \multirow[t]{2}{*}{$30(28 \mathrm{M}, 2 \mathrm{~W})$} & $8(\mathrm{M})$ & \multirow[t]{2}{*}{$8(7 \mathrm{M}, 1 \mathrm{~W})$} & $3(\mathrm{M})$ \\
\hline FFS T3 & & & & & Tomato & & $30(24 \mathrm{M}, 6 \mathrm{~W})$ & & $8(7 \mathrm{M}, 1 \mathrm{~W})$ \\
\hline FFS T4 & & & & $\begin{array}{l}\text { Maize, } \\
\text { soybean }\end{array}$ & Onion & $23(7 \mathrm{M}, 16 \mathrm{~W})$ & $23(2 \mathrm{M}, 21 \mathrm{~W})$ & $5(\mathrm{~W})$ & $6(\mathrm{~W})$ \\
\hline FFS B1 & \multirow{5}{*}{$\begin{array}{c}\text { Burkina } \\
\text { Faso }\end{array}$} & \multirow{5}{*}{$\begin{array}{l}\text { Consultative } \\
\text { participation }\end{array}$} & $2013-2014$ & \multirow{3}{*}{\multicolumn{2}{|c|}{$\begin{array}{l}\text { Cotton, maize, } \\
\text { mucuna or } \\
\text { cowpea }\end{array}$}} & \multirow{3}{*}{\multicolumn{2}{|c|}{$\begin{array}{l}25(\mathrm{M}) \\
25(16 \mathrm{M}, 9 \mathrm{~W}) \\
20(\mathrm{M})\end{array}$}} & \multicolumn{2}{|l|}{$5(\mathrm{M})$} \\
\hline FFS B2 & & & 2014-2015 & & & & & \multicolumn{2}{|l|}{$6(4 \mathrm{M}, 2 \mathrm{~W})$} \\
\hline FFS B3 & & & 2011-2012 & & & & & $6(\mathrm{M})$ & \\
\hline \multirow[t]{2}{*}{ TOTAL } & & & & $6 \mathrm{FFS}$ & $4 \mathrm{FFS}$ & 153 (117M, 36W) & $79(44 \mathrm{M}, 35 \mathrm{~W})$ & $39(27 \mathrm{M}, 12 \mathrm{~W})$ & $21(12 \mathrm{M}, 9 \mathrm{~W})$ \\
\hline & & & & & & & Total sample & $60(39 \mathrm{M}, 21 \mathrm{~W})$ & \\
\hline
\end{tabular}

at levels acceptable to both men and women (if men thought the proportion was too high, they would take over the management of the legumes and deprive women of a source of income).

Based on the description of the two surveyed cases and according to Biggs' (1989) classification of farmer participation, the Burkinabe case is considered to be a "consultative" FFS (farmers were not involved in the choice of the thematic, the curricula was designed by experts, and farmers could give their feedback at the end of a cropping season) and the Togolese case a "collaborative" FFS (farmers were involved in the choice of the thematic, the curricula was designed based on their interests by facilitators, and farmers' feedback was included during the cropping season to modify the curricula if necessary). Both types of FFS were open to all volunteer farmers, without incentives to participate.

\subsection{Surveys of farms belonging to a diversified sample of former FFS participants}

The surveys of farms belonging to former FFS participants aimed to collect qualitative and quantitative data on farmers' practices (technical and strategical choices) regarding family crops grown in the rainy season (collective work managed by the farm head) and vegetables grown in the dry season (individual work and management). We also analyzed project documents and data collected in interviews with project stakeholders. We held focus group discussions with eight former consultative FFS groups and 11 former collaborative FFS groups to discuss their impressions of the FFS' implementation and process, topics, group dynamics, and relations with the facilitators. Seven FFS groups were selected based on the criteria that FFS implementation had followed their respective project's guidelines and that no major disturbing event occurred during the course of the FFS. The focus groups were used to identify the main changes and themes common to the seven surveyed FFS, and to specify how the FFS had been conducted from the participants' viewpoint.

The farms surveyed met the following sampling criteria: participation of a family member (usually husband or wife) in a vegetable gardening and/or rainy season FFS who was still present on the farm at the time of the survey. Sampling was based on contacts provided by the project staff and by the farmers themselves using the snowball method, as farmers know their peers best. Our sample does not claim to be representative of all farmers in the study areas; our sampling method may have had some biases regarding the representativeness of farmers, as may have had the methods used to target FFS participants in favor of well-off and educated farmers (Phillips et al. 2014). Moreover, only 60 interviews were carried out due to the constraints of long interviews and the length of the research project.

The final sample included 60 farms (Table 1) out of the 232 farms belonging to former FFS participants, i.e., a 26\% sampling rate. The 21 women included in the sample represent $35 \%$ of the total interviewees (and $31 \%$ of the participants of the sampled FFS). The average cultivated land in 2018 is 4 ha in the Togolese sample (between 1 ha and 8,75 ha) and 9,1 ha in Burkina Faso (between 4 ha and 13 ha). The survey was conducted through semi-structured interviews in three successive visits between January and June 2019 ( 2 to 7 years after the end of the FFS in Table 1). The first visit aimed at gathering data on farm history and characteristics and confirming the participation of one family member in the FFS. During the second visit, we collected information on changes in agronomic practices at the plot, cropping system and farm levels 
by establishing a retrospective record based on farmers' recollection of the successive changes in practices that had occurred since the beginning of their participation in the FFS. The interviews mostly focused on the practices experimented within the FFS (fertilization and pest management practices and legume cropping), but all farm sub-systems were addressed, including farm organization. During the third interview, the trajectory of change in practices was orally validated and completed if necessary. The data from the survey was anonymized after the end of the interviews.

\subsection{Analytical framework}

The changes in cropping system management practices were explored through three topics common to the seven sampled FFS identified during the focus group discussions and stakeholder interviews: pest and disease management; fertilization management; use of legumes in the rainy season cropping system (either pure cropping or intercropping). The situation before the FFS began was considered as the initial situation for each farm (starting point of the trajectory). The efficiencysubstitution-redesign (ESR) framework can be used to characterize agroecological transitions over a long period of time (Hill and MacRae 1996; Lamine 2011; Tittonell 2014). In our case, it was used to record gradual changes in the intensity of the observed changes in practices and their potential ability to foster a transformation of the cropping or farming system (Table 2 and 3). Efficiency optimizes the practices in the current system without transformation. Substitution replaces some inputs or practices with more efficient or more ecological ones requiring a readjustment of the system. Redesign includes technical and organizational reorganization of the system to enhance its synergies. The scaling was established on the basis of the recorded practices from the field study.

The scale for the use of pesticides (Table 3 ) is based on the type of pesticide used (synthetic pesticides, biopesticides or combined) and the mode of preparation of biopesticides (individual, collective, or both) that can be characterized according to the ESR framework. Biopesticides can substitute for conventional synthetic pesticides, but the collective preparation of biopesticides constitutes a redesign. The scale of fertilization (Table 2 and 3) refers to the strategy used by farmers in both types of cropping systems. Mineral fertilizers, available in all villages, represent the conventional fertilization practice and strategy, but in case of cashflow constraints, farmers use animal droppings or only slightly degraded residues (dump). Manure is collected from cattle sheds and is composed of crop residue fodder and bovine dung, more or less ripened. Compost can be prepared on the farm in piles or pits and consists of alternating layers of crop residues and manure, left for three months to compost (including turning over for vegetable gardening) or for one year (without turning, for rainy season crops). Manure and compost substitute for mineral fertilizers; however, the intensification or collective preparation of compost are considered a redesign.

The scale of the share of legumes in the cropping system (Table 2) considers legumes in two ways. First, we considered the introduction of pure legume cropping in the crop rotation. This triannual cotton-cereal-legume rotation was the aim of the FFS curricula in both countries. Second, we considered the total share of legumes in the cropping system, including cereal-legume intercropping and pure legume plots outside the main cereal-cotton rotation. Plots outside the main cereal-cotton rotation can be used for monocropping (this is often the case in women's legume plots) and pure cropping on separate plots, and are conventional legume cropping practices. The traditional intercropping practice consists of perpendicular lines of a legume crossing the cereal rows every 4-6 m, whereas intercropping in alternate rows or alternate seed holes is considered a redesign (in terms of sowing geometry, relative densities of both crops) and is distinguished by the proportion of legumes in the cereal plot (the main crop). The proportions of each crop per hectare were calculated considering a spacing of $0.8 \mathrm{~m} \times 0.4 \mathrm{~m}$, with two plants per seed hole $(62,500$ plants per hectare).

\section{Results and discussion}

Farmers' trajectories of change in practices are presented in Figs. 2 and 3. We present the diversity of farmers' trajectories of change in practices, followed by the description of the processes occurring in rainy season (Fig. 2) and vegetable (Fig. 3) cropping systems. The last section discusses the results in light of the local contexts and the implementation of FFS, as well as the relevance of trajectories of change in practices for FFS assessment.

\subsection{Farmers' trajectories of change in practices after they participated in FFS}

\subsubsection{Diversity of farmers' changes in practices}

At first glance, Figs. 2 and 3 show that almost all surveyed farmers $(57 / 60)$ changed their practices through diversified trajectories. This reveals active on-farm innovation processes during and after the farmers' participation in the FFS. When the FFS began, the use of mineral fertilizers and synthetic pesticides was widespread in both cropping systems. In the initial situation, legume cropping was most commonly practiced through separate pure legume plots and/or cereals intercropped with legumes (often cowpea). The diversity of trajectories is visible in the number of steps or changes, ranging from 0 (no change) to 4 successive steps, and different trajectories can lead to the same arrival point. 
Table 2 Scale for coding farmers' practices after their participation to rainy season Farmer Field Schools. The scaling was established using the efficiency-substitution-redesign (ESR) framework (Hill and MacRae 1995, Tittonell 2014). The practices implemented within the FFS plots are highlighted in light gray (consultative FFS, Burkina Faso) and dark gray (collaborative FFS, Togo). The traditional intercropping practice consists of perpendicular lines of a legume crossing the cereal rows every 4-6 m, whereas intercropping in alternate rows or alternate seed holes is distinguished by the proportion of legume in the cereal plot (the main crop). Over $20 \%$ of legumes intercropped with cereals is equivalent to 1 row of legumes each 3-4 rows of cereals. Less than $20 \%$ of legumes intercropped with cereals is equivalent to 1 row of legumes each 5-10 rows of cereals

\begin{tabular}{|c|c|c|c|c|}
\hline \multirow{3}{*}{$\begin{array}{l}\text { SHARE OF LEGUMES IN THE RAINY } \\
\text { SEASON CROPPING SYSTEM }\end{array}$} & \multicolumn{2}{|l|}{ Practice } & \multirow[t]{2}{*}{ Code } & \multirow[t]{2}{*}{ ESR level } \\
\hline & Legumes in cropping system & Type of cereal-legume intercropping & & \\
\hline & \multicolumn{2}{|l|}{ No legumes } & A & Conventional \\
\hline & \multicolumn{2}{|l|}{ Pure legumes aside } & $\mathrm{B}$ & \\
\hline & Intercropping only & Traditional & $\mathrm{C}$ & \\
\hline & Intercropping and pure legumes aside & Traditional & $\mathrm{D}$ & \\
\hline & & $<20 \%$ leg. & $\mathrm{E}$ & Redesign \\
\hline & & $>=20 \%$ leg. & $\mathrm{F}$ & \\
\hline & Pure legumes in rotation & & G & \\
\hline & $\begin{array}{l}\text { Intercropping and pure legumes in } \\
\text { rotation }\end{array}$ & $\begin{array}{l}<20 \% \text { leg. } \\
>=20 \% \text { leg. }\end{array}$ & $\begin{array}{l}\mathrm{H} \\
\mathrm{I}\end{array}$ & \\
\hline \multirow{9}{*}{$\begin{array}{l}\text { FERTILISATION MANAGEMENT } \\
\text { PRACTICES FOR RAINY SEASON } \\
\text { CROPS }\end{array}$} & \multicolumn{2}{|l|}{ Mineral fertilizer only } & 1 & Conventional \\
\hline & \multicolumn{2}{|l|}{ Mineral fertilizer and dump / droppings } & 2 & \\
\hline & \multirow{2}{*}{\multicolumn{2}{|c|}{$\begin{array}{l}\text { Mineral fertilizer and occasional manure } \\
\text { Mineral fertilizer and yearly manure }\end{array}$}} & 3 & Efficiency \\
\hline & & & 4 & \\
\hline & \multicolumn{2}{|c|}{ Mineral fertilizer, yearly manure, manure purchase } & 5 & \\
\hline & \multirow{2}{*}{\multicolumn{2}{|c|}{$\begin{array}{l}\text { Mineral fertilizer and compost ( } 1 \text { pit }) \\
\text { Mineral fertilizer, compost ( } 1 \text { pit), manu }\end{array}$}} & 6 & Substitution \\
\hline & & & 7 & \\
\hline & \multirow{2}{*}{\multicolumn{2}{|c|}{ Mineral fertilizer and compost ( $>1$ pit) }} & 8 & Redesign \\
\hline & & & 9 & \\
\hline
\end{tabular}

The most outstanding arrival points of the trajectories were the cases of cropping system redesign:

- Collective preparation and use of biopesticides (practice H, Fig. 3) were introduced by some groups of farmers for reasons of economy of scale (to reduce individual workloads) and to improve the efficiency of biopesticides. In this configuration, all of the farmers spray on the same day. As biopesticides mainly have a repellant effect on insects, this avoids insects finding shelter in a "reservoir" plot and returning rapidly. We consider this collective preparation and use of biopesticide as both a collective and a spatial redesign (farmers considered pest dynamics in the entire gardening area rather than in their individual plots). It involves collective learning. However, this option requires group cohesion and coordination.

- Some farmers diversified to a triennial cotton-cereallegume crop rotation (practices G, H and I, Fig. 2), which we consider to be a redesign of the cropping system as it involved a change in scheduling (planning the crop rotation) and also changes in storage and marketing of legumes, and possibly more fodder production and storage.

- While producing compost in one pit (practices 6 and 7, Fig. 2) was considered a substitution of fertilizers, increasing on-farm composting (i.e., having two or more pits) was considered a redesign because it led to changes in the organization of other farm activities in order to obtain and transport the necessary amounts of biomass (crop residues can be left in the field, fed to animals or used for composting) and to produce and transport large quantities of compost (increasing the workload in the dry season, which can interfere with other activities) (practices 8 and 9, Fig. 2).

- Collective compost production (practice 8, Fig. 3 ) is also considered as redesign when it relies on the collective organization of women who pool their resources to obtain access to larger quantities of good quality organic fertilizers, which they may not be able to obtain individually for their vegetable gardening. It is a collective innovation to overcome individual constraints.

Finally, we highlight the diversity of farmers' practices with respect to biopesticide recipes (prepared with chili pepper, onion, garlic, neem leaves and/or pits in various proportions, maceration times), modes of composting (in piles or pits or both, bokashi, in gardens, in the field or on-farm), and variety of cereal-legume intercrops (cowpea, soybean and/or peanut in rows or alternating seed holes). The diversity of trajectories of 
Table 3 Scale for coding farmers' practices after their participation to vegetable gardening Farmer Field Schools. The scale was established using the efficiency-substitution-redesign (ESR) framework (Hill and MacRae 1995, Tittonell 2014). The practices implemented within the FFS plots are highlighted in gray

\begin{tabular}{|c|c|c|c|}
\hline \multirow{9}{*}{$\begin{array}{l}\text { PEST MANAGEMENT PRACTICES } \\
\text { FOR GARDENING }\end{array}$} & Practice & Code & ESR level \\
\hline & No gardening & A & 1 \\
\hline & No treatment & $\mathrm{B}$ & \multirow[t]{2}{*}{ Conventional } \\
\hline & Systematic treatment with synthetic pesticides & $\mathrm{C}$ & \\
\hline & Reasoned treatment with synthetic pesticides & $\mathrm{D}$ & Efficiency \\
\hline & Biopesticides and synthetic pesticides combined & $\mathrm{E}$ & \multirow[t]{2}{*}{ Substitution } \\
\hline & Biopesticides, individual preparation & $\mathrm{F}$ & \\
\hline & Biopesticides, individual and collective preparation & $\mathrm{G}$ & \multirow[t]{2}{*}{ Redesign } \\
\hline & Biopesticides, collective preparation & $\mathrm{H}$ & \\
\hline \multirow{8}{*}{$\begin{array}{l}\text { FERTILIZATION MANAGEMENT PRACTICES } \\
\text { FOR GARDENING }\end{array}$} & No gardening & 1 & 1 \\
\hline & Dump and animal droppings & 2 & \multirow[t]{3}{*}{ Conventional } \\
\hline & Mineral fertilizer only & 3 & \\
\hline & Animal droppings and mineral fertilizer & 4 & \\
\hline & Compost and mineral fertilizer & 5 & Efficiency \\
\hline & Manure only & 6 & \multirow[t]{2}{*}{ Substitution } \\
\hline & Compost only & 7 & \\
\hline & Collective compost & 8 & Redesign \\
\hline
\end{tabular}

change in practices revealed the range of choices farmers made considering their individual farm situations and constraints, and the diversity of farms that each FFS included in its implementation and that our sample managed to cover.

\subsubsection{Farmers' trajectories in the rainy season cropping system (Fig. 2)}

The targeted practice for the rainy season FFS (detailed in Table 2) is in color in Fig. 2, and the comparison between the different FFS underlines the influence of the type of FFS implementation on farmers' trajectories of change in practices.

In our sample of former participants $(n=17)$ of three consultative FFS (Fig. 2 blocks a, b, c), farmers' trajectories are short and mostly horizontal toward the occasional "(practice 3,8 farms) or annual (practice 4, 3 farms) use of manure. In B2 and B3 (Fig. 2 blocks b and c), the trajectories are horizontal or diagonal toward the use of manure, and two farmers made no changes at all. In B1 (Fig. 2 block a), farmers reported that the facilitator had a rather authoritarian manner of implementing the FFS. The trajectories are horizontal and limited to increased use of animal droppings and manure, with the exception of one farmer whose diagonal trajectory went beyond the FFS goals (Fig. 2 block a, practice 7). This farmer had started to compost on-farm because his farm had acquired a compost pit through support provided by another project after the end of the FFS. He was also the only farmer to purchase manure from Peuhl breeders.

In the consultative FFS sample, farmers' legume cropping practices and cotton pest management practices did not change much. The farmers said they grow cowpea in plots outside the main cereal-cotton rotation, and they had not increased cereal-legume intercropping. Two farmers who had previously not grown any legumes started pure cowpea cropping (practice B Fig. 2 block a and c). No farmer in our sample started growing Mucuna or soybean. Three farms reduced their share of legumes after the FFS, and reverted to, or kept, their cropping system with no legumes (practice A, fig. 2). Moreover, legumes represented an average of only $8 \%$ of the plants per cultivated hectare, only one farm reached $20 \%$ of legumes per cropped hectare. In comparison, cotton plants represented an average of $49 \%$ of plants per cropped hectare in 2018 (range 29\% to 67\%). Even if the cowpea plots were included in the rotation with cereals and cotton, the overall impact of the practice would have been low.

Despite the focus on biopesticides and treatments according to thresholds on the curriculum, the consultative FFS we sampled in Burkina Faso did not challenge the widespread use of synthetic pesticides in cotton cropping. No farmers tested biopesticides in their own cotton field, and no farmers used them on cowpea (one farmer conducted one trial). Farmers mentioned two main reasons. First, as the production of biopesticides is labor-intensive (involving the collection or purchase of plant parts, grinding them, maceration, filtering large amounts), the workload would increase drastically if biopesticides were applied to an entire cotton field, several times over one cropping season. Biopesticides are also less concentrated than synthetic pesticides and require heavier equipment. In fact, biopesticides increased work effort and required more sprayings per cropping cycle. Second, cotton is often the main cash crop for farmers, who therefore approach the management of this particular crop with caution. Cotton companies, who provide farmers with inputs on credit, are also reluctant to encourage any practice that could put cotton yields at risk and its technicians discourage farmers from experimenting. 
For the collaborative FFS (Fig. 2 blocks d, e, f), farmers' trajectories of change in practices are more diversified. T1 and T2 (Fig. 2 blocks d and f) had the longest and most diversified trajectories of our study. Diagonal (direct) trajectories appear rare, and most farmers first make a horizontal move toward increasing the use of organic fertilizer, and then a vertical change toward more legume cropping.

In our 22-person sample of former participants in collaborative FFS (Fig. 2 blocks d, e, f), 8 farmers reached the FFS goal of annual compost fertilization (practice 6), and 11 went further (practices 7, 8 and 9: more than one compost pit, purchase of manure), thus redesigning their farm functioning to intensify compost production. Two elements contributed to this result. First, the Togolese project explicitly targeted compost production and use, identified as a key practice for farm agroecological transition in both FFS curricula and other farmscale project activities. Farmers were given support in digging their first compost pit, which they then replicated to create two or three pits. In the project's area of intervention, a total of 183 groups of neighbors (3-5 people from different households) received financial support to purchase a donkey cart, aimed at reducing the workload needed to transport residues from the field to the pit, and then to transport the compost back to the field. Second, in northern Togo, both land saturation and loss of soil fertility have reached higher levels than in western Burkina. Togolese farmers are long time users of manure and are familiar with its agronomic properties. This is clear when considering the starting points of Togolese farmers (Fig.2 d, e, f), which already mention the use of manure, whereas this was the arrival point for the Burkinabe farmers in our sample (Fig. $2 \mathrm{a}, \mathrm{b}, \mathrm{c})$. We hypothesize that Togolese farmers were more likely to accept the additional workload required for the production, transport and use of compost.

Farmers in the consultative FFS sample increased the share of legumes in the cropping system with cereal-legume intercropping (16 farmers) and pure legume cropping (15 farmers); however, only five started a cereal-cotton-legume rotation (practices G, H and I). In 2018 in our collaborative sample, the total share of legumes represented on average $20 \%$ of the plants per cropped hectare, and three farms exceeded $30 \%$. Cotton represented on average $21 \%$ of plants per cropped hectare (range 0-57\%). Intercropping is common in northern Togo, and most farmers started with traditional intercropping. In our sample, cereal-legume intercropping accounted for $52 \%$ of the total cereal area, and 16/22 farmers had changed their intercropping practices to increase the average proportion of legumes by $26 \%$ per hectare of intercropped land. Farmers use a variety of intercropping schemes, the most frequent being four or five rows of maize for one row of soybean (respectively 4 and 5 farmers).

The reliance on synthetic pesticides for cotton crop management is also present in Togo, as gardeners who

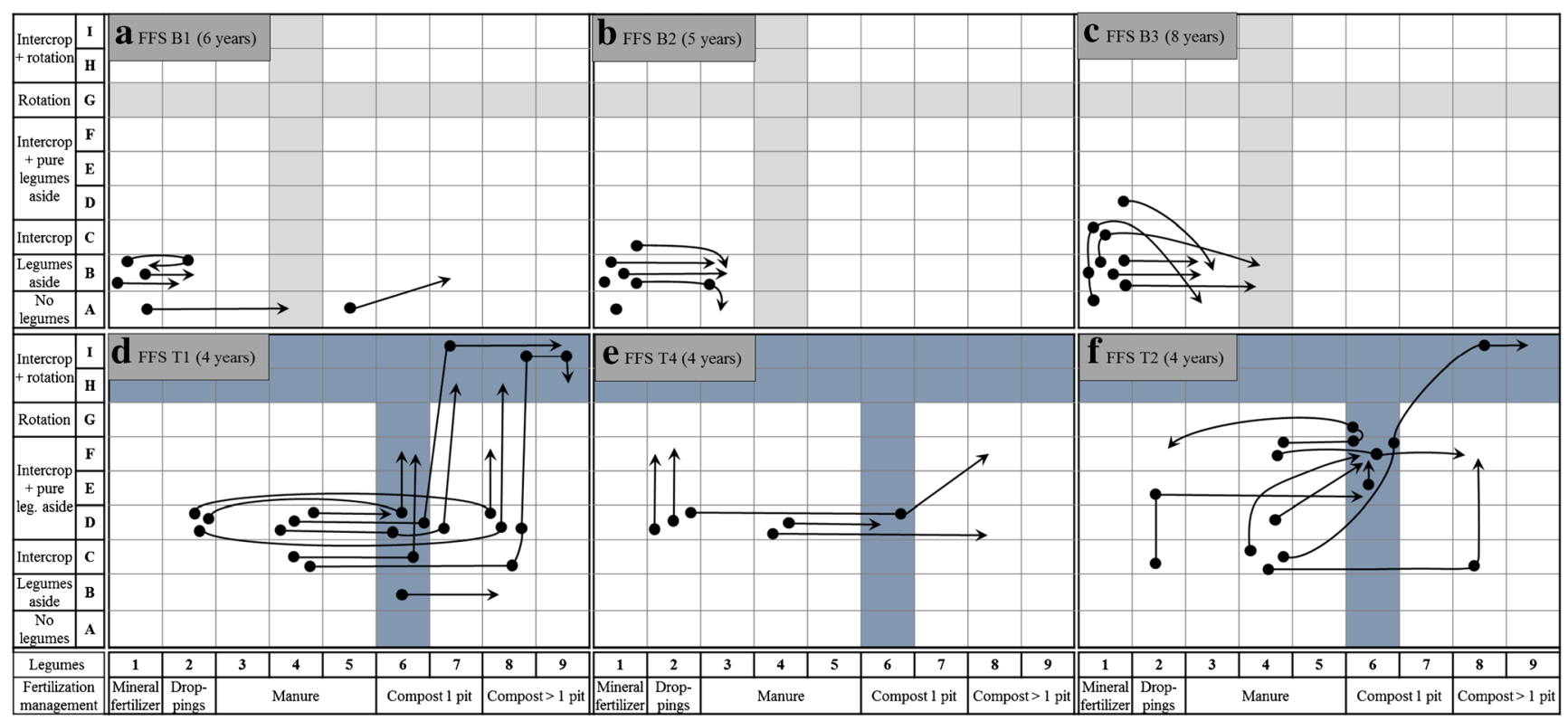

Fig. 2 Farmers' trajectories of change in agricultural practices after Farmer Field Schools for rainy season crops in 3 consultative FFS in western Burkina Faso (top line: block a, b, c) and 3 collaborative FFS in northern Togo (bottom line: block d, e, f). The grey boxes display the FFS code described in table 1 and the time span between the start of the FFS and the survey. The scaling and codes for the two axis on legume cropping and fertilization management practices are described in table 2.b. The practices implemented within the FFS plots are highlighted in the rows and columns in light grey (consultative FFS, Burkina Faso) and dark grey (collaborative FFS, Togo). Each trajectory represents one individual farmer. The first black dot represents the farmer's practice at the beginning of the participation to the FFS, the following dots (if there are any) represent the successive changes in practices made by the farmer according the survey, and the arrow represents the last change in practices made at the time of interviewing. The dots do not correspond to each cropping season, only to the successive changes in practices made by farmers 


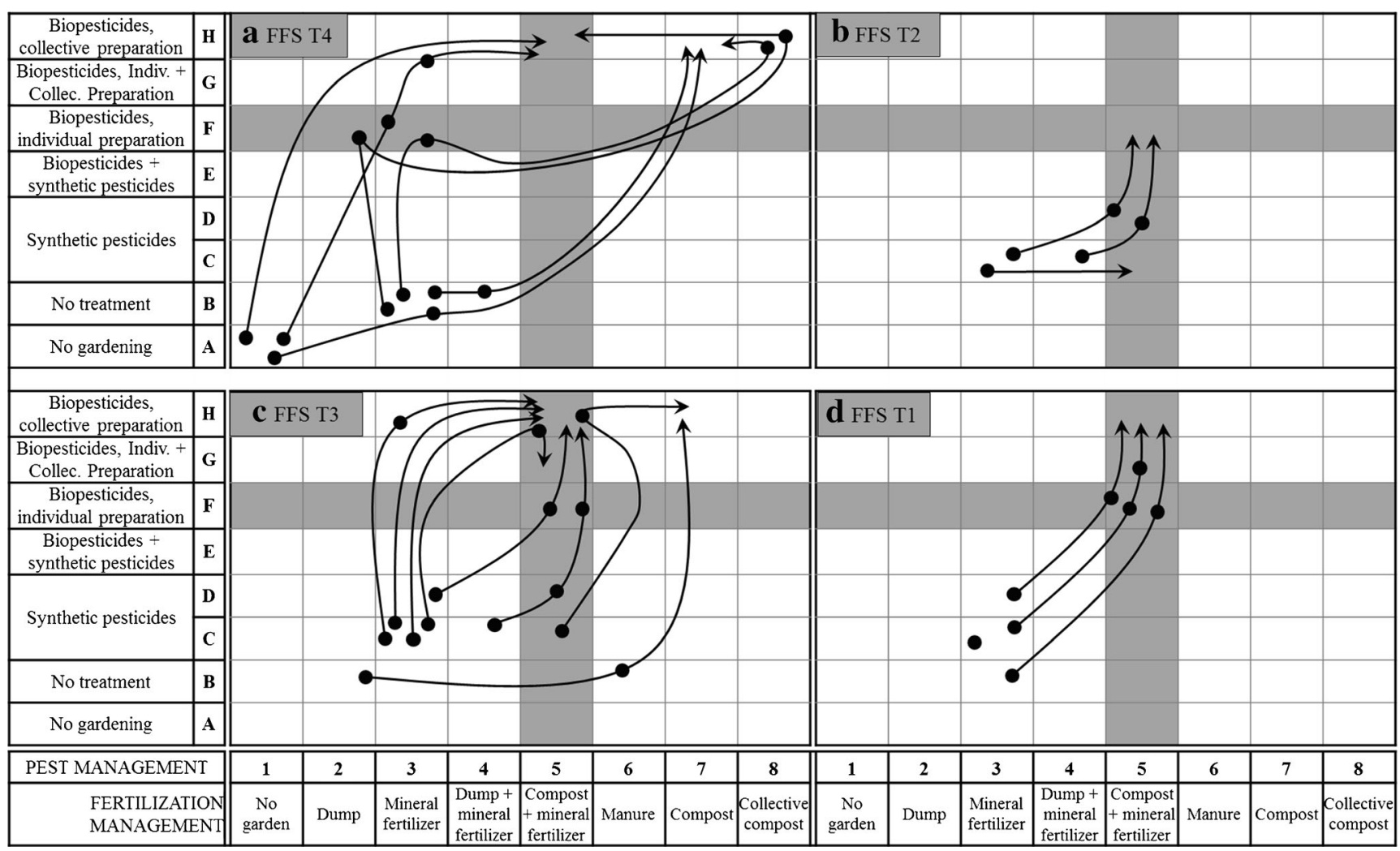

Fig. 3 Farmers' trajectories of change in practices after Farmer Field Schools for vegetable gardening in 4 collaborative FFS in northern Togo. The gray boxes display the FFS code described in table1. The scaling and codes for the two axis on legume cropping and fertilization management practices are described in Table 2.a. The rows and columns in gray highlight the practices implemented within the FFS plots. The time span between the start of the FFS and the survey is 5 years for all represented FFS. Each trajectory represents one individual farmer. The first black dot represents the farmer's practice at the beginning of the participation to the FFS, the following dots (if there are any) represent the successive changes in practices made by the farmer according the survey, and the arrow represents the last change in practices made at the time of interviewing. The dots do not correspond to each cropping season, only to the successive changes in practices made by farmers successfully use biopesticides on vegetables are, like Burkinabe farmers, nonetheless reluctant to use it on cotton. Two farmers replaced some synthetic pesticide applications with biopesticide. The first did so because synthetic treatments had been ineffective on his neighbors' fields (so he had "nothing to lose"). Yet despite being a success in 2017, he did not want to do it again. The second farmer sells some of the provided synthetic pesticides to feed his family in the lean season. It is possible to use biopesticides on cowpea, as two farmers did in the collaborative sample, but the workload is high even for 0.25 ha.

In general, there was little distinction between men and women interviewees concerning rainy season crops in the six FFS (Fig. 2) because these crops rely on family labor (all active family members work on these collective fields) and the means of production are managed by the farm head. For consultative FFS, trajectories shifted from conventional to efficiency phases for all farmers in the sample except one $(n=16)$. For collaborative FFS, changes in the use of compost (substitution) and the intensification of its production (redesign) were most common $(n=19)$, but are not necessarily accompanied by an increase in the share of legumes in the cropping system. Replacing a proportion of cereals by legumes in intercropping $(n=16)$ was more common than the redesign of the cropping system to rotate cereals, cotton, and legumes $(n=5)$.

\subsubsection{Farmers' trajectories in the vegetable gardening cropping system (Fig. 3)}

As an individual activity, dry season vegetable gardening is considered separately from the functioning of the whole farm, although some common resources (organic fertilizer and workforce) may be used. The gardener's gender influences the choice of practices. Women often chose to grow onions and leafy vegetables, linked to their individual strategies to limit their expenses (onions produce the same yield with organic or mineral fertilizers, and do not need to be sprayed). Men prefer more profitable crops, most often tomatoes but also carrots, cabbage, and chili peppers, which require the purchase of seeds, mineral fertilizers and pesticides.

Regarding crop protection and pest management, in T1, T3 and T4 (Fig. 3 blocks a, c, d), the learning and experimentation process during the FFS triggered forms of collective innovation in gardeners' practices. Seventeen farmers went beyond 
the goal of the FFS and started collective pest management (practice H), but this did not happen in T2 (Fig. 3 block b). Regarding fertilization management, 16 farmers used a combination of organic and mineral fertilizers (practice 5), five farmers started using only organic fertilizer (practices 6,7 and 8 ). The farmers had difficulty managing their vegetable gardens only using organic fertilizer, especially when they grew tomatoes or chili peppers.

In T1 (Fig. 3 block d), the trajectories first reached the goal of the FFS on fertilization and pest management (practice F5), and farmers then agreed to start collective biopesticide preparation and use (practice H). In T3 (Fig. 3 block c), the gardeners also shifted toward collective pest management practices (practice $\mathrm{H}$ ) directly or with an intermediate step. The FFS group in T4 (Fig. 3 block a) was composed of women who grew onions, which explains why they were more prone to only using organic fertilizers. The interviewees' trajectories spin around the center of the fig. (3a block a). In addition to collective biopesticide treatments (practice $\mathrm{H}$ ), a subgroup of women actively engaged in forms of collective organization for compost production (practice 8) to access good quality organic fertilizers, which, at the farm level, are primarily reserved for cereals and are managed by the farm head (a man). Collective composting allows women to pool the small quantities of animal droppings or manure they are allowed to use in order to produce a larger quantity of better decomposed compost (with crop residues), which they share. Men, on the other hand, can decide to use the farm's compost in their garden and occasionally benefit from the workforce of other family members. However, the collective production of compost requires collective organization, which led two women to return to individual fertilization management because the group failed to start the compost production in time before the start of the 2019 gardening season (3a block a, practice 7 and 5).

The differences in the trajectories among the four gardening FFS (Fig. 3) we studied underline the importance of competent facilitators in the FFS process. In village T2 (Fig. 3 block b), the facilitator was less motivated and the group of gardeners in the FFS were all close neighbors and members of the same extended family. The other gardeners in the same village had little contact with them and did not learn about the content and conclusions of this FFS. Figure 3 block b shows that the gardeners of this FFS made fewer changes and did not engage in collective compost or pest management.

Because vegetable gardening is an individual activity, and due to the short cropping cycles (2-4 months), gardeners can make changes rapidly and can afford to take some controlled risks. In three villages (Fig. 3 blocks a, c, d), the gardeners shifted easily from conventional to redesign in the collective production and use of biopesticides $(n=19)$. For fertilization management, most gardeners $(n=16)$ preferred to partially replace mineral fertilizers with compost, and only five did so completely. Gardening plots are small (on average $0,1 \mathrm{ha}$ ) so it is easier to provide high doses of organic fertilizers. Synthetic pesticides are accessible and affordable for small areas, but nothing prevents farmers from using non-conventional pest management techniques. In the dry season, the higher workload required to prepare and use biopesticides does not interfere with other major activities. Moreover, farmers explained that reducing the dose of mineral fertilizers and using biopesticides had economic and marketing benefits: decreased costs, less rotting, better product appearance and quality, and therefore sometimes the possibility of increasing their prices or quantities sold.

\subsection{Implications for supporting on-farm innovation processes}

\subsubsection{Understanding farmers' rationales}

The fact that changes in practices are a gradual trajectory is a common feature of farm transitions (Lamine 2011; Chantre and Cardona 2014). In West Africa, farmers manage their farm in a context of high uncertainty and risks (Falconnier et al. 2015). Therefore, an entire technological package is rarely adopted as it would involve greater risks, mainly during the period of learning and adaptation of farmers' practices and implementation at the scale of the whole target cropping system. Moreover, farmers who volunteer to participate in an FFS are not choosing to engage in a transition pathway with a clear objective in mind, unlike transitions to organic agriculture for instance. In most cases, economic or work criteria guide their choices, rather than the agronomic and environmental relevance of a given technique (Chantre et al. 2015).

The methodology presented here is based on farmers' narratives about their past and present practices, in a context where no records are available to cross-check the interview data. The risk is that farmers may not remember exactly past events and reconstruct their history a posteriori (Chantre et al. 2015). To limit this bias, the interviews focused on the changes considered as significant by the farmers, rather than on factual and technical descriptions of the successive states of the cropping system (changes are more memorable), with questions to temporally ground farmers' changes in practices (example: "did you change this practice in the same cropping season than the FFS started?" "Did you wait to see the results in the FFS plot?"). The survey was completed in three successive visits to avoid tiring farmers and to facilitate the recollection of memories. Although it remains difficult to ascertain that such a narrative is faithful to what really happened, this type of long-term narrative is well documented as a relevant way to rebuild a trajectory (Chantre et al. 2015).

We also considered that the observed trajectories could have other causes than the way FFS were implemented. Farmers were asked if they had participated in other 
development projects, and particular attention was paid to farmers' justifications of their changes in practices. Moreover, our results need to be viewed in light of the changes in local contexts over the same period (2011-2019). In Togo, soybean cropping has expanded in recent years due to both local market and export opportunities. The use of herbicides is also less widespread in northern Togo, and consequently does not disturb farmers' weed management when intercropping. Likewise, in western Burkina Faso, farmers' use of manure is not necessarily directly linked to the FFS, as it is a more general recent trend in the region (Blanchard et al. 2014).

The changes toward the production and use of compost in the collaborative FFS sample were possible because they did not challenge the dominant sociotechnical regime, and the activities of the Togolese project helped remove constraints to on-farm compost production. Sociotechnical regimes result from the interactions of the determinants of innovation and create a lock-in situation that precludes the development of alternative practices (Vanloqueren and Baret 2009). The use of compost or manure is possible and is not discouraged by the dominant sociotechnical regime in West African cotton areas, and Burkinabe farmers with atypical organic fertilization practices were found to have also overcome the transport and organizational constraints (Blanchard et al. 2017).

In contrast, the reluctance of farmers to change their pest management practices in cotton cropping is explained by a complex and multiscale sociotechnical lock-in. The cotton value chain is dominated by cotton companies that decide and impose cotton crop management strategies, especially pest management, that rely on reductionist paradigms and promote intensive use of inputs to maximize yields. Significantly, this has led cotton companies to impose $B t$ cotton cropping, which reinforced the rejection of biopesticide use for cotton pest management. During the 2009-2016 period, when Bt cotton was grown in Burkina Faso, technicians recommended two chemical treatments for Bt cotton (farmers undertook on average 1.3) and six for non-Bt cotton (farmers undertook on average 5.1) (Vognan and Fok 2019). Using biopesticides (which increased the workload required for preparation and spraying) became even less attractive to them than using Bt cotton with a reduced workload. Once the cropping of Bt cotton ceased, farmers reverted to their previous conventional crop protection practices. At the farm level, cotton also plays an important role in farmers' soil fertility management, both directly through crop rotation (Falconnier et al. 2015), and indirectly as it gives farmers access to inputs such as mineral fertilizers, some of which are used on food crops. A bad cotton yield can mean that farmers fall into debt and lose their access to mineral fertilizers, which would reduce the farm's food security.

Future research on the possibilities for agroecological transitions in cotton cropping areas should integrate all actors of the value chain and consider the financial risks for both farmers and cotton companies. Key practices for farmers' transitions must be identified (Chantre et al. 2015) and need to include the workload, work distribution and the hard labor required, especially for women. The development of innovation niches outside the dominant sociotechnical regime is possible but requires the creation of alternative networks of actors (Meynard et al. 2012) and insuring socio-economic benefits for farmers. Niches, such as dry season agroecological vegetable gardening in Togo, play a crucial role in stimulating agroecological innovations to challenge existing lock-ins in the dominant sociotechnical regime (Vanloqueren and Baret 2009).

The diversity of practices shows that farmers did not simply adopt techniques from the FFS, but experimented and adapted their practices, thus creating new practices. Deffontaines et al. (2020) point out that redesign of cropping systems may result from either the gradual addition of simple technical changes or a specific systemic change at the cropping system scale. This is consistent with our findings, and backs the idea of supporting farmers' learning and experimentation processes (Catalogna et al. 2018). Even if the existing network of stakeholders does not make it possible to challenge the dominant sociotechnical regime, the diversity of farmers' practices and trajectories of change evidenced reinforces the assertion that advisory services should be adapted to farmers' (very) local conditions and reinforce farmers' innovation capacities (Birner et al. 2009).

\subsubsection{Influence of the type of implementation of FFS on farmers' trajectories}

We show that farmers who participated in collaborative FFS had longer and more diverse trajectories of change in practices, with some farmers redesigning their cropping systems. As discussed earlier, other elements may have influenced these results, namely the quality of facilitation and the importance of the targeted crops in the dominant sociotechnical regime. Despite these differences in context, our results show that one of the strengths of collaborative FFS is to set in motion trajectories of change in practices that go beyond content addressed during the FFS. Therefore, we argue that, to some extent, the type of FFS implementation (consultation or collaboration) influenced farmers' trajectories of change in practices. We attribute this to the place of the diagnosis in the process of implementing FFS and the role of farmers in decision making regarding FFS curricula and field trials. For the consultative FFS, the curriculum was defined by scientists and diffused in a standardized way across a large region, and this preset curriculum lessened the relevance of a local diagnosis with FFS groups. The case of Mucuna cropping shows that it is crucial to take farmers' preferences into consideration; its insertion in crop rotations was not discussed with farmers but 
emerged from the literature due to its soil fertilization properties. Farmers, however, were not interested in a crop that is unsuitable for human consumption and requires transforming to be fed to animals. A diagnosis at the stage of project and local FFS conception, albeit with some farmer consultation, and the development by researchers of a technological package of "good agricultural practices" led to a complete, and thus complex, standardized cropping system to be transferred to farmers. Deffontaines et al. (2020) show that the complexity of the practices promoted by top-down extension services limits their adoption, and Glover et al. (2016) state that the concept of adoption is overly focused on individual decisions, neglecting social aspects of technological change. In addition to being complex, the proposed practices may seem unrealistic since farmers' constraints and capacities, such as workload or access to biomass and organic fertilizers, are not considered. Likewise, biopesticides produced by farmers were the only treatment included in the curriculum, although given the workload required and the reluctance among the chain of actors, farmers would not realistically be able to use them.

Our case studies on consultative FFS in Burkina Faso showed that in some cases, FFS are used to transfer technologies (Rogers 2003) while relying on farmer-to-farmer facilitation. It has been recognized that sharing knowledge with other farmers can speed up changes (Chantre and Cardona 2014; Mawois et al. 2019); however, our results question the promotion of FFS as a ready-to-use method. Even if the elements are well implemented, a standardized method is no guarantee that the intervention will be profitable for farmers simply because it uses farmers' participation to facilitate acceptance but, in the end, does not give farmers the power of decision (which distinguishes collaboration from consultation). In a case study in Togo, Nederlof and Dangbégnon (2007) state that "pre-analytical choices" limit farmers' power of decision. The fact that FFS have been integrated in the national agricultural policies in some countries (including Burkina Faso) should thus be tempered because FFS can be used in a logic of technology transfer, with limited consultation of farmers, and without seeking to reinforce farmers' competencies and autonomy (as was the case in the three consultative FFS we analyzed in Burkina Faso). A shift from a top-down research and extension model to an AIS based on participatory principles requires a social, organizational and institutional change within international and national research systems, advisory services and farmers' organizations (Hounkonnou et al. 2012). Innovation cannot be decided, but has to be managed strategically by reinforcing the capacities of stakeholders, starting with farmers and their organizations (Klerkx et al. 2010; Toillier et al. 2018).

The strength of the Togolese FFS lies in their collaborative approach with farmers, implying that farmers chose the crops and topics to implement in the FFS, resulting in a location- specific FFS. This collaborative participation of farmers implies that the content of each FFS is not known from the start (i.e., not specified in the project documents), which forces the facilitator into a position of listening to and reformulating requests in the face of emerging demands from farmers (Kilelu et al. 2014). Khumairoh et al. (2019) modified the FFS approach to make adaptations suited to local conditions for complex rice systems in Indonesia. However, we note that all of their adaptations were chosen for their agronomic relevance and not according to the farmers' own criteria, for example, their socio-economic priorities. Our results also emphasize the importance of a competent facilitator, trained in participatory approaches and aware of power asymmetries in the relationship between facilitator and group (Barnaud and Van Paassen 2013). Elite capture and less inclusive participation of women and young farmers can also challenge the relevance of FFS curricula (Phillips et al. 2014).

In collaborative FFS, the process of collectively diagnosing, experimenting and learning is to some extent comparable to a step-by-step design process (Meynard et al. 2012) in which farmers' learning processes and changes in practices are the main outputs rather than a side-effect of knowledge production. Stating that "simple practices adopted by farmers are part of a slow trajectory of change involving gradual acquisition of knowledge", Deffontaines et al. (2020) suggest that innovation design should include the co-design of a succession of simple changes instead of a complex final system that farmers do not want to implement all at once. Step-bystep collective design of locally adapted cropping systems is in line with FFS core principles, which put farmers and their farming systems on center stage (Van den Berg and Jiggins 2007). To support changes in practices and transition pathways that are manageable for farmers, the Togolese case study also emphasizes the relevance of complementary activities to the FFS (in this case, organizational and financial support for donkey carts and compost pits), and thus the complementarity of different development and advisory services in a single project. Our results highlight the usefulness of supporting small steps of the transitions and the importance of the quality of innovation support initiatives.

\subsubsection{Trajectories of changes in practices to overcome the limits of FFS assessments}

By using farmers' trajectories of change in practices to assess and compare the effects of two types of FFS implementation, this study opens new perspectives for FFS assessments. According to van den Berg et al. (2020) and Bakker et al. (2020), assessments of FFS tend to focus on their direct and short-term effects. Most rely on knowledge tests, adoption rates or the measure of quantitative indicators of agronomic or economic performance (yield, gross margin, input expenses) as a proxy for the adoption of new techniques. 
However, while such assessments of FFS are rigorous and worth undertaking when the objective is to measure differences in quantifiable indicators, our results show that in many cases, farmers' trajectories of change in practices went beyond the topics of the FFS. Figures 2 and 3 capture practices that diverge from FFS curricula, adaptations to farmers' own constraints or context that are desirable in a logic of reinforcing farmers' competencies and increased autonomy. Measuring an adoption rate would not have revealed this variety of changes in practices, nor provided insights on the dynamics of these processes (Glover et al. 2016).

Three factors reveal the relevance of trajectories of change in practices for FFS assessment. First, the gradual changes made by farmers after participating in FFS underscore the relevance of long-term evaluation. Second, the gradual rate of farmers' changes may guarantee the robustness of the changes. Lamine (2011) argues that gradual changes enable farmers to manage the redesign of their system. The robustness of farmers' changes is a relevant criterion in the context of development projects, in which reversible changes in practices may take place during the project period. Lastly, in a context of high uncertainty, farmers are reluctant to take risks and use adaptive management strategies (Darnhofer et al. 2010). These strategies are more visible in medium and long-term trajectories than through a one-off evaluation at the end of the project.

Reconstructing farmers' trajectories of change in practices is thus one way to grasp whether a process of change has begun in farms, whether the FFS intervention contributed to the change, and if so, how. This approach also makes it possible to identify the steps and lockouts to on-farm innovation for agroecological transitions to target relevant knowledge and competences for farmers. We argue that trajectories of change in practices are complementary to existing assessment methods of FFS and make it possible to deepen understanding of processes of change occurring in participating farms. Farmers' trajectories are particularly relevant in the case of collaborative FFS where the curriculum is not predetermined or standardized. To go even further, participatory approaches to evaluate the effects of FFS are also relevant and complement conventional FFS assessment methods (Mancini and Jiggins 2008).

\section{Conclusion}

By establishing farmers' trajectories of change in practices, we analyzed two contrasting FFS implementation types and explained their effects, or absence thereof, in regard to agroecological transitions. For consultative FFS, the changes were limited to the use of manure, whereas for collaborative FFS, there was a variety of changes involving the production and use of compost, biopesticides, and inclusion of legumes in the cropping system through intercropping or pure cropping. Collaborative FFS were able to set in motion trajectories of change in practices that go beyond content addressed during the FFS. Redesign of cropping systems included increasing on-farm compost production, collective pest management, intercropping and crop rotations. Collaborative FFS can therefore be seen as step-by-step design processes for locally adapted cropping systems and can bring about changes not only at the cropping system level, but also at the farm scale where other innovation processes might take place. Given the characteristics of family farms in West Africa, we suggest analyzing the processes of change at the farm level as a research perspective that could also be used for comprehensive impact assessments of innovation support initiatives.

This article is the first to establish farmers' trajectories of change in practices through a retrospective survey to assess the effects of FFS. This approach is dynamic and allows for a better understanding of on-farm innovation processes than standard adoption surveys. It will be a challenge for innovation support initiatives to take into account the diversity of farmers' trajectories of change revealed in our results.

Acknowledgments This study was conducted within the scope of a scientific and financial partnership with FAO (Plant Production and Protection Division and Regional Office for Africa, through the GEF and IFAD funded Resilient Food Systems Programme) and the NGO AVSF (Agronomes et Vétérinaires Sans Frontières). The authors thank Enoque Coulibaly, student at University of Dédougou (Burkina Faso) for his contribution to the investigation phase of the study.

Authors' contributions Conceptualization, T.B., P.D. and S.D.T.; Methodology, S.D.T. and T.B.; Investigation T.B.; Writing -Original Draft, T.B.; Writing -Review \& Editing T.B., P.D. and S.D.T.; Funding Acquisition, P.D.; Resources P.D.; Supervision, T.B., P.D. and S.D.T.

Funding This study was conducted within the scope of a scientific and financial partnership with FAO (Plant Production and Protection Division and Regional Office for Africa, through the GEF and IFAD funded Resilient Food Systems Programme) and the NGO AVSF (Agronomes et Vétérinaires Sans Frontières). T.B. is a former paid volunteer at AVSF.

Data availability The datasets generated during and analyzed during the current study are available from the corresponding author on reasonable request.

\section{Declarations}

Conflict of interests None.

Consent to participate The participants to the study were informed about the conditions and purpose of the research and gave informed oral consent to participate to the research. The data was anonymized after the end of the interviews. 


\section{References}

Altieri MA (2002) Agroecology: the science of natural resource management for poor farmers in marginal environments. Agric Ecosyst Environ 93:1-24. https://doi.org/10.1016/S0167-8809(02)00085-3

Bakker T, Blundo Canto G, Dugué P, de Tourdonnet S (2020) To what extent is the diversity of farmer field schools reflected in their assessment? A literature review. J Agr Educ Ext 1-21. https://doi.org/ 10.1080/1389224X.2020.1858890

Barnaud C, Van Paassen A (2013) Equity, power games, and legitimacy dilemmas of participatory natural Resource Management. Ecol Soc 18. https://doi.org/10.5751/ES-05459-180221

Berthet ETA, Barnaud C, Girard N, Labatut J, Martin G (2016) How to foster agroecological innovations? A comparison of participatory design methods. J Environ Plan Manag 59:280-301. https://doi. org/10.1080/09640568.2015.1009627

Biggs S D (1989) Resource-poor farmer participation in research: a synthesis of experiences from nine national agricultural research systems. International Service for National Agricultural Research (ISNAR). OFCOR Series No. 3 (Comparative Study), the Hague

Birner R, Davis K, Pender J, Nkonya E, Anandajayasekeram P, Ekboir J, Mbabu A, Spielman DJ, Horna D, Benin S, Cohen M (2009) From best practice to best fit: a framework for designing and analyzing pluralistic agricultural advisory services worldwide. J Agric Educ Ext 15:341-355. https://doi.org/10.1080/13892240903309595

Blanchard M, Coulibaly K, Bognini S et al (2014) Diversité de la qualité des engrais organiques produits par les paysans d'Afrique de l'Ouest???: quelles conséquences sur les recommandations de fumure ??? Biotechnol Agron Soc Environ 12. https://popups.uliege.be:443/ 1780-4507/index.php?id=11654

Blanchard M, Vall É, Tingueri Loumbana B, Meynard J-M (2017) Identification, caractérisation et évaluation des pratiques atypiques de gestion des fumures organiques au Burkina Faso : sources d'innovation ? Autrepart 81:115. https://doi.org/10.3917/autr.081. 0115

Catalogna M, Dubois M, Navarrete M (2018) Diversity of experimentation by farmers engaged in agroecology. Agron Sustain Dev 38 . https://doi.org/10.1007/s13593-018-0526-2

Chantre E, Cardona A (2014) Trajectories of French field crop farmers moving toward sustainable farming practices: change, learning, and links with the advisory services. Agroecol Sustain Food Syst 38: 573-602. https://doi.org/10.1080/21683565.2013.876483

Chantre E, Cerf M, Le Bail M (2015) Transitional pathways towards input reduction on French field crop farms. Int J Agric Sustain 13: 69-86. https://doi.org/10.1080/14735903.2014.945316

Darnhofer I, Bellon S, Dedieu B, Milestad R (2010) Adaptiveness to enhance the sustainability of farming systems. A review: Agron Sustain Dev 30:545-555. https://doi.org/10.1051/agro/2009053

Deffontaines L, Mottes C, Della Rossa P, Lesueur-Jannoyer M, Cattan P, le Bail M (2020) How farmers learn to change their weed management practices: simple changes lead to system redesign in the French West Indies. Agric Syst 179:102769. https://doi.org/10.1016/j.agsy. 2019.102769

Falconnier GN, Descheemaeker K, Van Mourik TA et al (2015) Understanding farm trajectories and development pathways: two decades of change in southern Mali. Agric Syst 139:210-222. https://doi.org/10.1016/j.agsy.2015.07.005

Glover D, Sumberg J, Andersson JA (2016) The adoption problem; or why we still understand so little about technological change in African agriculture. Outlook Agric 45:3-6. https://doi.org/10.5367/ oa. 2016.0235

Hill SB, MacRae RJ (1996) Conceptual framework for the transition from conventional to sustainable agriculture. J Sustain Agric 7:81-87. https://doi.org/10.1300/J064v07n01_07
Hounkonnou D, Kossou D, Kuyper TW, Leeuwis C, Nederlof ES, Röling N, Sakyi-Dawson O, Traoré M, van Huis A (2012) An innovation systems approach to institutional change: smallholder development in West Africa. Agric Syst 108:74-83. https://doi.org/10.1016/j. agsy.2012.01.007

Khumairoh U, Lantinga EA, Suprayogo D, Schulte RPO, Groot JCJ (2019) Modifying the farmer field school method to support onfarm adaptation of complex rice systems. J Agric Educ Ext 25: 227-243. https://doi.org/10.1080/1389224X.2019.1604391

Kilelu CW, Klerkx L, Leeuwis C (2014) How dynamics of learning are linked to innovation support services: insights from a smallholder commercialization project in Kenya. J Agric Educ Ext 20:213-232. https://doi.org/10.1080/1389224X.2013.823876

Kiptot E, Hebinck P, Franzel S, Richards P (2007) Adopters, testers or pseudo-adopters? Dynamics of the use of improved tree fallows by farmers in western Kenya. Agric Syst 94:509-519. https://doi.org/ 10.1016/j.agsy.2007.01.002

Klerkx L, Aarts N, Leeuwis C (2010) Adaptive management in agricultural innovation systems: the interactions between innovation networks and their environment. Agric Syst 103:390-400. https://doi. org/10.1016/j.agsy.2010.03.012

Lamine C (2011) Transition pathways towards a robust ecologization of agriculture and the need for system redesign. Cases from organic farming and IPM. J Rural Stud 27:209-219. https://doi.org/10.1016/ j.jrurstud.2011.02.001

Mancini F, Jiggins J (2008) Appraisal of methods to evaluate farmer field schools. Dev Pract 18:539-550. https://doi.org/10.1080/ 09614520802181277

Mancini F, Van Bruggen AHC, Jiggins JLS (2007) Evaluating cotton integrated Pest management (IPM) farmer field school outcomes using the sustainable livelihoods approach in India. Exp Agric 43: 97-112. https://doi.org/10.1017/S001447970600425X

Mawois M, Vidal A, Revoyron E et al (2019) Transition to legume-based farming systems requires stable outlets, learning, and peer-networking. Agronomy for sustainable development 39. https://doi.org/10. 1007/s13593-019-0559-1

Meynard J-M, Dedieu B, Bos AP (2012) Re-design and co-design of farming systems. An overview of methods and practices. In: Darnhofer I, Gibbon D, Dedieu B (eds) Farming systems research into the 21st century: The New Dynamic. Springer Netherlands, Dordrecht, pp 405-429. https://doi.org/10.1007/978-94-007-4503218

Nederlof ES, Dangbégnon C (2007) Lessons for farmer-oriented research: experiences from a west African soil fertility management project. Agric Hum Values 24:369-387. https://doi.org/10.1007/ s10460-007-9066-0

Phillips D, Waddington H, White H (2014) Better targeting of farmers as a channel for poverty reduction: a systematic review of farmer field schools targeting. Dev Stud Res 1:113-136. https://doi.org/10.1080/ 21665095.2014.924841

Rogers EM (2003) Diffusion of innovations, 5th edn. Free Press, New York

Röling N (2009) Pathways for impact: scientists' different perspectives on agricultural innovation. Int J Agric Sustain 7:83-94. https://doi. org/10.3763/ijas.2009.0043

Salembier C, Elverdin JH, Meynard J-M (2016) Tracking on-farm innovations to unearth alternatives to the dominant soybean-based system in the Argentinean Pampa. Tracking on-farm innovations to unearth alternatives to the dominant soybean-based system in the Argentinean Pampa. Agron Sustain Dev 36:36. https://doi.org/10. 1007/s13593-015-0343-9

Schut M, Rodenburg J, Klerkx L, van Ast A, Bastiaans L (2014) Systems approaches to innovation in crop protection. A systematic literature review. Crop Prot 56:98-108. https://doi. org/10.1016/j.cropro.2013.11.017 
Tittonell P (2014) Ecological intensification of agriculture - sustainable by nature. Curr Opin Environ Sustain 8:53-61. https://doi.org/10. 1016/j.cosust.2014.08.006

Toillier A, Faure G, Chia E (2018) Designing and organizing support for collective innovation in agriculture. In: Faure G, Chiffoleau Y, Goulet F, et al. (eds) Innovation and development in agricultural and food systems. éditions Quae. https://doi.org/10.35690/978-27592-2960-4

Van den Berg H, Jiggins J (2007) Investing in farmers - the impacts of farmer field schools in relation to integrated Pest management. World Dev 35:663-686. https://doi.org/10.1016/j.worlddev.2006. 05.004

van den Berg H, Phillips S, Dicke M, Fredrix M (2020) Impacts of farmer field schools in the human, social, natural and financial domain: a qualitative review. Food Secur 12:1443-1459. https://doi.org/10. 1007/s12571-020-01046-7
Vanloqueren G, Baret PV (2009) How agricultural research systems shape a technological regime that develops genetic engineering but locks out agroecological innovations. Res Policy 38:971-983. https://doi.org/10.1016/j.respol.2009.02.008

Vognan G, Fok M (2019) Performance différenciée du coton Bt en début de diffusion : cas du Burkina Faso. Cah Agric 28:26. https://doi.org/ 10.1051/cagri/2019026

Waddington H, Snilstveit B, Hombrados J, et al (2014) Farmer field schools for improving farming practices and farmer outcomes: a systematic review. Campbell Syst Rev https://doi.org/10.4073/ CSR.2014.6

Warner K (2007) Agroecology in action: extending alternative agriculture through social networks. MIT, Cambridge, Mass

Publisher's note Springer Nature remains neutral with regard to jurisdictional claims in published maps and institutional affiliations. 